\title{
Ecuadorian infant mortality linked to socioeconomic factors during the last $\mathbf{3 0}$ years
}

\author{
Natalia Romero-Sandoval 1 \\ iD https://orcid.org/0000-0001-6881-6581 \\ Diego Del Alcázar 2 \\ https://orcid.org/0000-0002-8157-3622 \\ Jacob Pastor 3 \\ iD https://orcid.org/0000-0002-4415-7793 \\ Miguel Martín 4 \\ https://orcid.org/0000-0001-6156-0739
}

\footnotetext{
1 Facultad de Ciencias Médicas de la Salud y de la Vida. Universidad Internacional del Ecuador. Av. Jorge Fernandez and Simon Bolivar. Quito 170113. Ecuador. E-mail: nromero@uide.edu.ec

2 Facultad de Ciencias Sociales y Comunicación. Universidad Internacional del Ecuador. Quito, Pichincha, Ecuador

3 Instituto Geografico Militar. Quito, Pichincha, Ecuador.

4 Unidad de Bioestadística. Facultad de Medicina. Universidad Autonoma de Barcelona. Bellaterra, Catalunya, Spain.
}

\begin{abstract}
Objectives: to analyze the difference among geographical units and the evolution of infant mortality rate (IMR) based on Ecuadorian censuses (1990-2001-2010).

Methods: artificial Neural Network analyzed the impact of sociodemographic factors over the variability of IMR. Poisson regression analyzed the variation of the standardized $\operatorname{IMR}(\operatorname{sIMR})$

Results: the decrease in the national IMR was $63.8 \%$; however, $42.8 \%$ provinces showed an increase in 2001-2010. The variability was explained mainly by illiteracy decrease. The adjusted RR between provincial SIMR with illiteracy and poverty revealed a trend towards the unit.

Conclusions: the variation of IMR reflects a complex interaction of the sociodemographic factors.

Key words Infant mortality, Ecuador
\end{abstract}

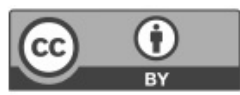




\section{Introduction}

Infant mortality rate (IMR) is defined as the number of infant deaths in the first year of life for every 1000 live births. According to the United Nations Interagency Group for Child Mortality Estimation, the IMR world-wide has decreased since 1990 from an estimated rate of 63 deaths per 1000 live births to 32 deaths per 1000 live births in 2015.1 Meanwhile in Ecuador, a developing country, the IMR has dropped down from an estimated of 30.24 deaths per 1000 live births in 1990 to 10.95 per 1000 live births in 2010, as reported by the National Institute of Statistics and Censuses of Ecuador (INEC, by its Spanish acronym) ${ }^{2}$

IMR is related to multiple genetic, environmental, and socioeconomic factors.3-5 For example, in developing countries an increase in education levels leads to decreases in marriage at a young age, first sexual experience, first birth and a better economic environment for the woman, all which lead to decrease of infant mortality. 6

Although a strong correlation has not been found between poverty reduction and lower IMR, for middle- and lower-income countries a $10 \%$ increase of the gross domestic product seems to be correlated with a reduction of $10 \%$ in IMR. Similarly, an increase in inequality is correlated with an increase of the IMR.5-7

Lower socioeconomic outcomes and higher IMR had been reported as disparities among ethnic minorities, like afro-descendants or indigenous social groups. 8,9 In Latin America and in Ecuador without exception, indigenous groups exhibit higher rates of poverty, lower education outcomes, higher fertility rates and limited access to basic health services compared to their non-indigenous counterparts. 10

In Ecuador, $7 \%$ of the population self-identify as indigenous, of them, almost $75 \%$ were poor based on unsatisfied basic needs (UBN) at 2010. Percentage of illiteracy in the indigenous population is $20.4 \%$ compared to $5.1 \%$ of the non-indigenous population, and an IMR 1.5 to 3 times higher than the national rate; when considering 1997 figures. ${ }^{11}$

Policies of inclusion to foster equity and poverty reductions have been implemented in Ecuador over the last ten years. 12 These policies have allowed a reduction of around 4.9 points in the Gini index between 2005 and 2010.13

In this context, we decide to analyze the quantitative contribution of illiteracy, poverty by unsatisfied basic need (UBN) and indigenous ethnicity proportion to the variability of IMR in years 1990,
2001 and 2010, by implementing an Artificial Neural Network model (ANN).

Additionally, in order to compare the risk of infant mortality among those with illiteracy and poverty we implemented an ecological analysis using a standardized IMR (SMR) at three temporal cut-off points (1990, 2001 and 2010).

\section{Methods}

We implemented an ecological study using data from three population censuses published by INEC, in 1990, 2001 and 2010. The data is made available in two structured digital formats (official sources): (1) Datasets of live births and general deaths grouped by sex.14 (2) Census Database provide data of social indicators (illiteracy and poverty). Ethnicity was included only in 2001 and 2010.15

Data were available for the 21 provinces (spatial ecological unit) confirming Ecuador for the years 1990, 2001 and 2010. Currently (2017), Ecuador is divided into 24 provinces; however, this study only considers the 21 provinces defined in the year 1990 . We also have excluded from the analysis all the areas belonging to unlimited jurisdictions. The unlimited areas are three and refer to the most recent geographic boundaries published by INEC, and not to the 1990 administrative boundaries as this data is not available in geographic information system format. We argue that this discrepancy is negligible since the un-delimited areas hold less than $1 \%$ of the total population $(0.72 \%$ in 1990$)$. For this analysis, the Galápagos Islands were excluded due to sociodemographic and economic differences with the continental Ecuadorian territory, and the lack of sufficient observations to include it in the analysis.

The spatial ecological unit was the province, which is the traditional geographical unit for political and administrative purposes and were 21 .

Illiterate: Person older than 15 years who cannot read and write. 15

Poverty by UBN: A person is considered poor by UBN if they live in a household with the following features: a household head with two or less years of education and one employed person for every four or more people living at home; living in a house made of irregular material such as cane walls; having a child between 6 to 12 years old who is not attending school; more than three people living per room; and, if the house does not have a connection to the water supply network or uses latrines or toilet facilities without a sanitation system. 16

Indigenous ethnicity: People living in a household whose head self-describes as indigenous. 15 
Illiteracy, poverty and indigenous ethnicity factors are presented in percentages.

The Artificial Neural Network model aims to weight each the factors that explain to the IMR variability. ANN are mathematical non-linear models that analyze the variability of the dependent variable, based on the connection of the variables to be studied. ${ }^{17,18}$ In this analysis the independent variables are illiteracy, poverty and share of indigenous population, and the dependent variable was provincial infant mortality crude rates. The variability is expressed between individual provinces for each census.

We performed an indirect standardization of the IMRs (SMR) at every province, taking as reference the population of the whole country. We show the change of each provincial SMR between the census $2001-1990$ and $2010-2001$.

First, we analyze the co linearity between illiteracy and poverty by Pearson coefficient. Second, we did an adjustment of the SMR infant mortality of 21 provinces, applying to Poisson regression model, given that the number of events occurring in disjoint intervals of space-time are independent, 19 in order to examine the adjusted relative risk (ARR) of SMR related to illiteracy and poverty percentages, by census years. The results were expressed as ARR and its $95 \%$ confidence interval. As indicated, ethnicity data was not available until the census of 2001, therefore it was not included in this analysis. We used the IBM SPSS Statistics 20 (IBM Corp., Armonk, NY, USA), to run the models.

\section{Results}

Ecuador's IMRs for years 1990, 2001 and 2010, both for the whole country and by gender, are shown in Table 1. The Table shows a decreasing IMR with a total decrease of $63.8 \%$ (19.29 deaths per 1000 live births) nationally, from 1990 to 2010 .

Illiteracy, poverty, and indigenous ethnicity percentages are presented in Table 2. Between 1990 and 2010 , illiteracy shows a reduction of $42.7 \%$, with a bigger drop among women (44.2\%) than men $(39.6 \%)$. Poverty declined from 1990 to 2010 in $24.5 \%$, Indigenous ethnicity proportion remained constant at approximately $7 \%$.

Table 2 presents the proportion of the national IMR variability explained by each of three factors studied in the three cut-off points. For 1990, the illiteracy explained the $66.2 \%$ of the variation of the national IMR compared to $33.8 \%$ of the variability explained by poverty. When the three factors are considered, IMR's variability for the year 2000 was explained in $45.2 \%$ by Illiteracy, in $39.1 \%$ by poverty and in $15.7 \%$ by the proportion of the indigenous ethnic group. Meanwhile, 2010 data showed that IMR variability for illiteracy and poverty remained the same as 2001 . However, it increased by $5.1 \%$ in the proportion of the indigenous ethnic group.

The variability of SMR by provinces respect to the country in the periods 1990-2001 and 2001-2010 is shown in Figure 1. In the period 1990-2001, of 21 provinces, 14 presented a decrease of the SMR with a variation between $7 \%$ and $45 \%$, while 7 provinces had an increase of the SMR with a variation between $2 \%$ and $21 \%$. In the period $2001-2010,9$ of 21 provinces showed a decrease of the SMR between $2 \%$ and $35 \%$, whereas in 12 provinces increased the SMR between $1 \%$ and $83 \%$. Nine $(42.8 \%$ ) provinces showed a decrease and then an increase and vice versa for $4(19.0 \%)$.

Previously, a correlation analysis between illiteracy and poverty was made $(\mathrm{r}=0.46, p<0.05)$. Table 2 also presents the results of fitting Poisson model for the SMR of infant mortality, expressing the results as relative risks and their $\mathrm{CI} 95 \%$, for each percentile point of change in the factors stated. We observe a significant increase in the SMR associated to higher percentages of illiteracy. In contrast, the poverty presents significant inverse associations with the rate studies. Nevertheless, both indicators showed a convergence to the unit in the relative risks during the studied period.

\section{Discussion}

One of the Millennium Development Goals established by the United Nations, in 2000, was to decrease the under-age of 5 mortality rate by two thirds between 1990 and 2015. While the reduction of infant mortality in most countries has been accelerated, most developing countries will need many years after 2015 to achieve that goal. ${ }^{20}$ This objective encompassed Latin America as well but was not achieved globally, ${ }^{5}$ apparently due to high proportions of neonatal deaths which suggest that more efforts should have focused at the earliest ages. ${ }^{21-23}$

In Ecuador, a country that went from being a lower-middle income country in the 1990's to an upper-middle income country in 2010,12 the results of this study showed a similar reduction of IMR figures with a drop from 30.24 to 10.95 per 1000 live births (63.8\%), between 1990 and 2010. Since 2006, there have been several new policies implemented directed to improve literacy, reduce poverty and inclusion of marginalized groups such as indigenous 
Table 1

Ecuador's Infant mortality rate (IMR) by gender in the years 1990, 2001, 2010.

\begin{tabular}{|c|c|c|c|c|c|}
\hline \multirow[t]{2}{*}{ Year } & \multicolumn{3}{|c|}{$\begin{array}{l}\text { Deaths within one year, per } 1000 \\
\text { live births (IMR) }\end{array}$} & \multirow[t]{2}{*}{ Number of births } & \multirow[t]{2}{*}{$\begin{array}{c}\text { Ecuador } \\
\text { population (millions) }\end{array}$} \\
\hline & Female & Male & Total & & \\
\hline 1990 & 27.95 & 32.44 & 30.24 & 263582 & 10.26 \\
\hline 2001 & 15.16 & 19.29 & 17.25 & 278160 & 12.55 \\
\hline 2010 & 10.26 & 11.61 & 10.95 & 292329 & 14.16 \\
\hline
\end{tabular}

Table 2

Illiteracy, poor people by unsatisfied basic needs and indigenous people rates, variability proportion of national IMR explained by them, and adjusted relative risk of standardized IMR, Ecuador census 1990-2001-2010.

\begin{tabular}{|c|c|c|c|c|c|c|c|c|c|c|}
\hline \multirow[t]{2}{*}{ Census year } & \multirow[t]{2}{*}{ Gender } & \multicolumn{4}{|c|}{ Illiteracy } & \multicolumn{2}{|c|}{ PP / UBN } & \multicolumn{3}{|c|}{ IndP } \\
\hline & & $(\%)$ & $\begin{array}{l}\text { VPN-IMR } \\
\text { by III }\end{array}$ & $\begin{array}{c}\text { Adjusted } \\
\text { RR } \\
(\mathrm{Cl} 95 \%)\end{array}$ & $(\%)$ & $\begin{array}{l}\text { VPN-IMR } \\
\text { by } \\
\text { PP/UBN }\end{array}$ & $\begin{array}{l}\text { Adjusted } \\
\text { RR } \\
(\mathrm{Cl} 95 \%)\end{array}$ & $(\%)$ & $\begin{array}{r}\text { VPN-IMR } \\
\text { by IndP }\end{array}$ & $\begin{array}{c}\text { Adjusted } \\
\text { RR } \\
(\mathrm{Cl} 95 \%)\end{array}$ \\
\hline \multirow[t]{4}{*}{1990} & Female & 13.79 & & & 78.41 & & & NA & & \\
\hline & Male & 9.47 & & & 80.48 & & & NA & & \\
\hline & Total & 11.78 & 0.662 & 1.039 & 79.43 & 0.338 & 0.981 & & & \\
\hline & & & & $\begin{array}{l}(1.035- \\
1.043)\end{array}$ & & & $\begin{array}{l}(0.978- \\
0.984)\end{array}$ & NA & NA & NA \\
\hline \multirow[t]{4}{*}{2001} & Female & 10.29 & & & 70.38 & & & 3.50 & & \\
\hline & Male & 7.65 & & & 72.19 & & & 3.33 & & \\
\hline & Total & 9.00 & 0.452 & 1.023 & & & 0.985 & & & \\
\hline & & & & $\begin{array}{c}(1.014- \\
1.033)\end{array}$ & 71.27 & 0.391 & $\begin{array}{l}(0.983- \\
0.988)\end{array}$ & 6.83 & 0.157 & NA \\
\hline \multirow[t]{4}{*}{2010} & Female & 7.70 & & & 59.17 & & & 3.57 & & \\
\hline & Male & 5.74 & & & 60.82 & & & 3.45 & & \\
\hline & Total & 6.74 & 0.420 & 1.026 & & & 0.989 & & & \\
\hline & & & & $\begin{array}{l}(1.011- \\
1.041)\end{array}$ & 59.98 & 0.373 & $\begin{array}{l}(0.986- \\
0.992)\end{array}$ & 7.03 & 0.208 & NA \\
\hline
\end{tabular}

$\mathrm{III}=$ Illiteracy; PP/UBN= Poor people by unsatisfied basic needs; IndP= Indigenous people; VPN - IMR= Variability proportion of national Infant Mortality Rate; NA= Not available. 


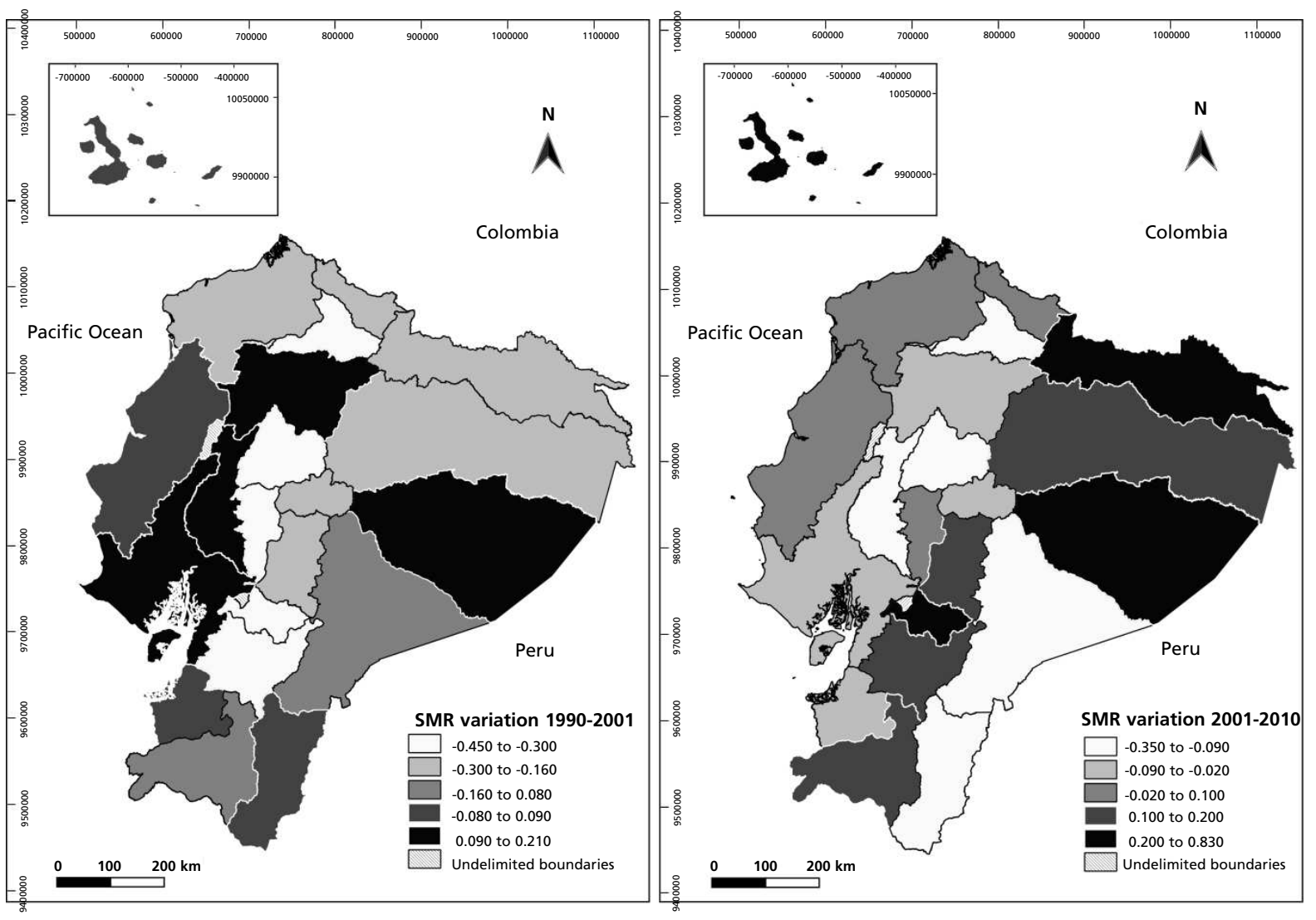

SMR= Standardized Infant Mortality Rate.

people, 24 factors whose influence on infant mortality have been described.7,9

In this context, we set out to analyze the contribution of these factors in the variability of the IMR. An ANN model helped us to establish the variability proportion of the national IMR explained by illiteracy, poverty and indigenous ethnicity percentages. Based on the ANN analysis, we identify that among the three factors studied, the predominant contributor to explain the variability of IMR in Ecuador is illiteracy.

These results motivated to quantify the relative weight of the study factors to explain the differences between the provincial rates standardized by age and sex, with respect to the country's overall. This analysis, carried out through a Poisson regression model, showed a trend of adjusted relative risks to the unit over time.

Plausible explanations to these results are: (1)
Intensification of governmental effort including health care, primarily health care. ${ }^{25}$ In the period studied, improvement in the health sector could produce a decrease in the magnitude of the intervention in education and the reduction of poverty. The effect of the intervention, through a reform of the health sector and the injection of funds, could be reflected in the reduction of infant mortality in less time, compared with the time required to observe the effect of reduction of both factors, poverty and illiteracy, over infant mortality. ${ }^{12,25}$ (2) Although a declining trend was found in IMR in Ecuador throughout the 3 periods of study, the evolution of IMR, in indigenous population the rate seems to remain stable.

Indigenous population has been linked with factors such as poverty and illiteracy, 10 all of which are barriers that make cooperation and coordination harder, especially when is related to health services. 
These factors are reflected in the lower access to maternal-infant services among indigenous compared to mestizos in Ecuador. ${ }^{24,26}$ In this analysis the proportion of indigenous ethnicity over the variability of IMR remained constant, and so its effect.

On the other hand, the SMR of the ecological units resulted disparities between the provinces in both periods (2001-1990 and 2010-2001). Almost half of the ecological units showed a decrease in the SMR during the first period, but the second showed an increase in the SMR, corresponding to a strong Government action focused on the social axis. This apparent contradiction could be explained by the improvement in the registration of births and deaths. The increase registration of births and deaths, motivated by a greater monitoring of the population, as well as the standardization of records of births and infant deaths have an initial effect of higher mortality, due to the visualization of the problems. This effect has been described in other countries. 27,28 However, this effect was not observed in all ecological units, which may be explained by the different degrees of structural modification of the records, over time.

Our study has the following limitations: (1) We analyzed the evolution of IMR considering the political-administrative division of Ecuador at 1990 which could change if the actual division is considered, the unavailable data regarding ethnicity in 1990 as well as the absence of other variables of the set of factors that influence the variability of the infant morbidity and mortality. However, we analyze

\section{References}

1. You D, Hug L, Ejdemyr S, Beise J. Levels and trends in child mortality. Report 2015. Estimates developed by the UN Inter-agency Group for Child Mortality Estimation; 2015.

2. Villacís B, Carrillo D, Martínez AG. Estadística demográfica en el Ecuador: diagnóstico y propuesta. Quito Inst Nac Estad Censos. 2011; 1-74.

3. Hanmer L, Lensink R, White H. Infant and child mortality in developing countries: Analysing the data for Robust determinants. J Dev Stud. 2003; 40; 101-18.

4. Rosano A, Botto LD, Botting B, Mastroiacovo P. Infant mortality and congenital anomalies from 1950 to 1994: an international perspective. J Epidemiol Community Health. 2000; 54: 660-6

5. Ward JL, Viner RM. The impact of income inequality and national wealth on child and adolescent mortality in low and middle-income countries. BMC Public Health. 2017; 17: 429 three of the main factors related to the IMR which can give public policies to continue with the reduction of IMR. 24,29 (2) In order to ensure the standardization of the definition of each variable studied, we took only three temporal cut-off points (1990, 2001 and 2010), which limits the analysis of the variability proportion of the IMR. (3) In the lasts census the quality of data acquisition and registration could have improved especially among provinces historically marginalized of informatics aspects which is reflected in an increase in the notification of the indicators studied.

An in-depth analysis of the relationship between illiteracy, poverty, and ethnicity over the time, and their relationship with infant mortality, allows the country a better understanding of the current situation, in order to create strategies to improve the living conditions of the population.

\section{Author's contribuition}

Romero-Sandoval N and Martín M conceived, design and coordinated the study. Romero-Sandoval $\mathrm{N}$, Martín $\mathrm{M}$ and Pastor J prepared the manuscript and contributed to the analysis of data. RomeroSandoval N, Martín M, Alcázar D and Pastor J were responsible for data management and statistical analysis. All the authors were involved in the interpretation of the data and drafting the manuscript. All authors read and approved the final manuscript.

6. Grépin KA, Bharadwaj P. Maternal education and child mortality in Zimbabwe. J Health Econ. 2015; 44: 97-117.

7. O'Hare B, Makuta I, Chiwaula L, Bar-Zeev N. Income and child mortality in developing countries: a systematic review and meta-analysis. J R Soc Med. 2013; 106: 408-14.

8. Rossen LM, Khan D, Schoendorf KC. Mapping geographic variation in infant mortality and related Black-White disparities in the US. Epidemiol. 2016; 27 (5): 690-6.

9. Haider SJ. Racial and ethnic infant mortality gaps and socioeconomic status. Focus. 2014; 31: 18-20.

10. Hall G. Indigenous peoples, poverty and human development in Latin America. (Springer; 2005)

11. Cujilema M, Dávila GO. La Salud de los Pueblos Indígenas. Salud En Glob. 2003; 169.

12. Malo-Serrano M, Malo-Corral N. Reforma de salud en Ecuador: nunca más el derecho a la salud como un privilegio. Rev Peru Med Exp Salud Publica. 2014; 31: 754-61. 
13. Albuja J, Navas A, Paguay D, Moreno A, Nájera P. Technological GINI: a study of the inequality in Ecuador. In: Democracy \& Government (ICEDEG), 2015 Second International Conference on 133-137 (IEEE, 2015).

14. Instituto Nacional de Estadística y Censos. Anuario de Estadísticas de Nacimientos y Defunciones (Generales y Fetales); 2011

15. Censos INE. (Instituto Nacional de Estadística y Censos). Población y Demografía. Instituto Nacional de Estadística y Censos. [Accessed: 4th March 2018]. Available at: http://www.ecuadorencifras.gob.ec/censo-de-poblacion-yvivienda/

16. Censos INE (Instituto Nacional de Estadística y Censos). Pobreza por Necesidades Básicas Insatisfechas. [Accessed: 4th March 2018]. Available at: http://www.ecuadorencifras.gob.ec/pobreza-por-necesidades-basicas-insatisfechas/

17. Zhang W, Barrion A. Function approximation and documentation of sampling data using artificial neural networks. Environ Monit Assess. 2006; 122: 185.

18. Cilimkovic M. Neural networks and back propagation algorithm. Inst. Technol. Blanchardstown Blanchardstown Road North Dublin 15; 2015. Available at: http://www.dataminingmasters.com/uploads/studentProjects/NeuralNetworks.p $\mathrm{df}$

19. Hayat MJ, Higgins M. Understanding poisson regression. J Nurs Educ. 2014; 53: 207-15

20. Lozano R, Wang H, Foreman KJ, Rajaratnam JK, Naghavi M, Marcus JR, Dwyer-Lindgren L, Lofgren KT, Phillips D, Atkinson C, Lopez AD, Murray CJ. Progress towards Millennium Development Goals 4 and 5 on maternal and child mortality: an updated systematic analysis. Lancet Lond Engl. 2011; 378: 1139-65.

21. Servan-Mori E, Torres-Pereda P, Orozco E, Sosa-Rubí SG An explanatory analysis of economic and health inequality changes among Mexican indigenous people, 2000-2010. Int J Equity Health. 2014; 13: 21.

Received on May 10, 2018

Final version presented on February 25, 2019

Approved on March 27, 2019
22. Ferre JC. Economic Inequalities in Latin America at the Base of Adverse Health Indicators. Int J Health Serv Plan Adm Eval. 2016; 46: 501-22.

23. Målqvist M. Neonatal mortality: an invisible and marginalised trauma. Glob Health Action. 2011; 4: 5724.

24. López-Cevallos DF, Chi C. Health care utilization in Ecuador: a multilevel analysis of socio-economic determinants and inequality issues. Health Policy Plan. 2010; 25: 209-18.

25. Lucio R, Villacrés N, Henríquez R. Sistema de salud de Ecuador. Salud Pública México. 2011; 53: S177-S187.

26. Kuang-Yao Pan W, Erlien C, Bilsborrow RE. Morbidity and mortality disparities among colonist and indigenous populations in the Ecuadorian Amazon. Soc Sci Med. 2010; 70 (3): 401-11.

27. Alvarez G, Harlow SD, Denman C, Hofmeister MJ. Quality of cause-of-death statements and its impact on infant mortality statistics in Hermosillo, Mexico. Rev Panam Salud Publica Pan Am. 2009; 25 (2): 120-7.

28. Wuhib T, Mc Carthy BJ, Chorba T, Sinitsina TA, Ivasiv. IV, McNabb SJ. Underestimation of infant mortality rates in one republic of the former Soviet Union. Pediatrics. 2003; 111 (5): e596-600.

29. Anderson I, Robson B, Connolly M, Al-Yaman F, Bjertness E, King A, et al. Indigenous and tribal peoples' health (The Lancet-Lowitja Institute Global Collaboration): a population study. Lancet Lond Engl. 2016; 388: 131-57. 